\title{
A distribuição dos eosinófilos nas diferentes fases de evolução do granuloma hepático em camundongos infectados pelo Schistosoma mansoni
}

\author{
Distribution of eosinophils at different stages of hepatic granuloma \\ evolution in mice infected with Schistosoma mansoni
}

\author{
Romero Antunes Barreto Lins ${ }^{1}$, Carmelita Bezerra de Lima Cavalcanti', \\ Jorge Luiz Silva Araújo-Filho', Mário Ribeiro de Melo-Júnior ${ }^{1,2}$ \\ e Maria Elizabeth Cavalcante Chaves ${ }^{1,3}$
}

\begin{abstract}
RESUMO
No presente estudo, avaliou-se a distribuição dos eosinófilos nas diferentes fases da formação do granuloma hepático de camundongos infectados pelo Schistosoma mansoni. A partir dos resultados obtidos sugerimos uma nova classificação para a evolução do granuloma hepático em camundongos montada a partir de fases descritas por outros autores. Em cada fase há um padrão diferente de distribuição dos eosinófilos. Na fase necróticoexudativa os eosinófilos encontram-se concentrados na periferia e no centro do granuloma e na área de necrose eles são escassos; na "produtiva" os eosinófilos estão ainda distribuídos de maneira difusa por todo o granuloma; na de cura por fibrose se concentram na periferia e no centro do granuloma. Os eosinófilos estavam em contato direto com os ovos em todos os estágios de evolução dos granulomas. Conclui-se então que a dinâmica dos eosinófilos possui papel importante na formação da reação granulomatosa do hospedeiro e resolução do processo inflamatório causado pelo ovo do parasita, além de acrescentar novos dados na classificação dos granulomas hepáticos.
\end{abstract}

Palavras-chaves: Esquistossomose. Granuloma. Anticorpo antiperoxidase eosinofílica. Anticorpo antiproteína catiônica eosinofílica.

\begin{abstract}
In the present study, the distribution of eosinophils at different stages of the formation of hepatic granuloma in mice infected with Schistosoma mansoni was evaluated. From the results obtained, we suggest a new classification for the evolution of hepatic granuloma in mice, constructed from the phases described by other authors. In each phase, there is a different pattern of eosinophil distribution. In the exudative-necrotic phase, the eosinophils are concentrated in the periphery and center of the granuloma, and are scarce in the necrotic area; in the productive phase, the eosinophils are dispersed throughout the granuloma; and in the cure due to fibrosis phase, the eosinophils are concentrated in the periphery and center of the granuloma. Eosinophils were found in direct contact with the eggs at all stages of evolution of the granuloma. It was concluded that the dynamics of eosinophils have an important role in forming the granulomatous reaction of the host and in resolving the inflammatory process caused by the parasite egg, as well as adding new data regarding hepatic granuloma classification.
\end{abstract}

Key-words: Schistosomiasis. Granuloma. Anti-eosinophil peroxidase antibody. Anti-eosinophil cationic protein antibody.

A esquistossomose é uma helmintose que acomete cerca de 200 milhões de pessoas em 73 países $^{3}{ }^{18}$. No Brasil, a área de transmissão contínua ocorre numa faixa extensa desde o Rio Grande do Norte até Minas Gerais e em diversos focos isolados espalhados pelo Pará, Maranhão, Piauí, Ceará, Goiás, São Paulo, Rio de Janeiro, Paraná, Santa Catarina e Rio Grande do Sul.
O sítio anatômico predileto dos vermes adultos de Schistosoma mansoni é a vasculatura mesentérica. Os ovos são evacuados no trato intestinal junto com as fezes, podendo ficar presos principalmente na parede do intestino ou no fígado, por onde chegam através da circulação porta. Caracterizando-se, portanto, como uma doença hepato-intestinal ${ }^{6}$.

1. Laboratório de Imunopatologia Keizo Asami, Universidade Federal de Pernambuco, Recife, PE. 2. Associação Caruaruense de Ensino Superior, Caruaru, PE. 3. Departamento de Bioquímica, Universidade Federal de Pernambuco, Recife, PE.

Endereço para correspondência: Prof. Mário Ribeiro de Melo-Júnior. Laboratório de Imunopatologia Keizo Asami (LIKA)/UFPE. Av. Morais Rêgo s/n, Campus Universitário, 50670-910 Recife PE.

Telefax: $55813271-8484 / 3271-8485$

e-mail:mariormj@gmail.com

Recebido para publicação em: 04/092007

Aceito em: 07/03/2008 
Tal doença é resultante da reação inflamatória granulomatosa aos ovos do parasita localizados nos tecidos e apresenta efeito acumulativo de lesões principalmente no fígado. Os ovos excretam um antígeno solúvel responsável pelo desencadeamento de um complexo fisiopatológico reacional que promoverá a formação do granuloma. Diariamente, cada casal de Schistosoma mansoni pode levar, à formação de cerca de 200 granulomas: ovo + reação granulomatosa que o envolve. Estes podem apresentar-se em pontos isolados ou difusos no intestino grosso e fígado ${ }^{16}$.

Dentre as células que compõem o granuloma, por volta de $50 \%$ são eosinófilos ${ }^{21}$. Estes secretam a proteína eosinofílica básica principal (major basic protein - MBP), a proteína eosinofílica catiônica (ECP - eosinophil cationic protein), a peroxidase eosinofílica (EPO - eosinophil peroxidase) e a neurotoxina derivada de eosinófílo (EDN - eosinophil-derived neurotoxin $)^{2}$. Demonstrou-se que a ECP causa, in vitro, a fragmentação e a ruptura do esquistossômulo do Schistosoma mansoni ${ }^{13}$. E juntamente com $\mathrm{H}_{2} \mathrm{O}_{2}$ a EPO mata o esquistossômulo ${ }^{8}$. Enquanto a MBP é tóxica a células de mamíferos ${ }^{21}$ e larvas de helmintos ${ }^{11}$ e provavelmente causa danos aos ovos de Schistosoma mansoni em humanos ${ }^{4}$.

Neste estudo, procuramos localizar as proteínas eosinofílicas ECP e EPO nas diferentes fases da formação do granuloma a fim de investigar a participação dos eosinófilos e de seus produtos de degranulação na destruição do ovo do Schistosoma mansoni ${ }^{7}$.

\section{MATERIAL E MÉTODOS}

Animais e infecção experimental. Vinte e quatro camundongos swiss machos (2 meses de idade) foram obtidos do biotério do LIKA/UFPE e infectados através da imersão da cauda por 2 horas em solução aquosa contendo suspensão com 50 cercárias da cepa SLM (São Lourenço da Mata) de Schistosoma mansoni previamente contadas com auxílio de lupa estereoscópica (Olympus SZ60).

Durante todo o experimento os camundongos foram alimentados com dieta comercial. Após 30 dias da infecção, grupos de dois animais foram sacrificados de 5 em 5 dias até 85 dias da infecção. 0 protocolo experimental foi aprovado pelo Comitê de ética em experimentação animal da Universidade Federal de Pernambuco.

Estudo imunohistoquímico. Após o sacrifício dos animais, os fígados foram retirados e fixados em formalina tamponada $\mathrm{pH} 7,2$ a 10\% num período máximo de 5 dias até 0 estudo histoquímico para não ocasionar perda de reatividade ao anticorpo ${ }^{22}$. Os fragmentos selecionados foram emblocados em parafina, em seguida os cortes de tecido $(4 \mu \mathrm{m})$ foram montados em lâmina histológica.

Para os estudos histoquímicos os corantes utilizados foram: hematoxilina-eosina (HE) para avaliação histológica geral e identificação dos granulomas e tricrômico de Masson para visualização das fibras colágenas. Na avaliação imunohistoquímica foram utilizados os anticorpos policlonais anti-EPO e anti-ECP (National Institutes of Health, Bethesda-USA). A reatividade dos anticorpos foi avaliada através da exposição dos tecidos a anticorpos secundários ligados à enzima fosfatase, que produz uma coloração avermelhada (Sigma, USA).

0 controle negativo da reação foi realizado seguindo-se o mesmo protocolo da imunohistoquímica suprimindo-se o anticorpo primário da reação.

Análise dos dados. Os padrões de distribuição dos eosinófilos foram avaliados a partir da intensidade da marcação e quantidade de células reativas, obtendo-se uma escala semiquantitativa da porcentagem média de células marcadas por campo em maior aumento (200x) no microscópio óptico.

A partir disso, os padrões de distribuição foram estabelecidos da seguinte forma: fraco $=15-20 \%$; moderado $=25-55 \% \mathrm{e}$ intenso $=60-95 \%$, segundo o protocolo estabelecido por Özer e $\operatorname{cols}^{17}$. Para análise da distribuição de eosinófilos, apenas foram consideradas as amostras que evidenciaram padrão de marcação intenso.

\section{RESULTADOS}

Ao analisar detalhadamente os cortes histológicos perante a evolução do granuloma hepático e revisar a literatura, adotamos neste trabalho uma classificação composta de duas fases pré-granulomatosas sugeridas por Lenzi e cols ${ }^{13}$ e três fases granulomatosas. São elas: fase pré-granulomatosa de reação inicial (Figura 1A e 1B), pré-granulomatosa exudativa (Figura 1C), necrótico-exudativa (Figura 1D), produtiva (Figura 1E) e de cura por fibrose (Figura 2F).

A morfologia da fase pré-granulomatosa varia bastante, dependendo da localização do ovo. As células inflamatórias são poucas e desorganizadas, traduzindo o mesmo comportamento aos eosinófilos (Figura 2A). Na fase pré-granulomatosa exudativa, o maior número de células compõe um padrão de distribuição difuso dos eosinófilos (Figura 2B). Na fase necrótico-exudativa os eosinófilos passam a se dispor em grande densidade na periferia e no centro do granuloma, sendo escassos na área de necrose (Figura 3B).

Para identificar neste trabalho os padrões de localização dos eosinófilos nas distintas fases de evolução do granuloma foi usada a técnica de imunohistoquímica. Duas proteínas foram os alvos dos anticorpos, a peroxidase eosinofílica (EPO) e a proteína catiônica eosinofílica (ECP), ambas armazenadas em grânulos no interior dos eosinófilos. Marcando-se estas proteínas, marca-se conseqüentemente o eosinófilo.

Esta hipótese foi comprovada, pois os padrões de marcação foram bastante semelhantes para os dois anticorpos: anti-EPO e anti-ECP (Figura 3A).

A invasão da área de necrose pelas células inflamatórias ao final da fase necrótico-exudativa e início da fase produtiva confere um padrão difuso de distribuição dos eosinófilos em torno do granuloma (Figura 4A) e no interior dos ovos (Figura 4B). 

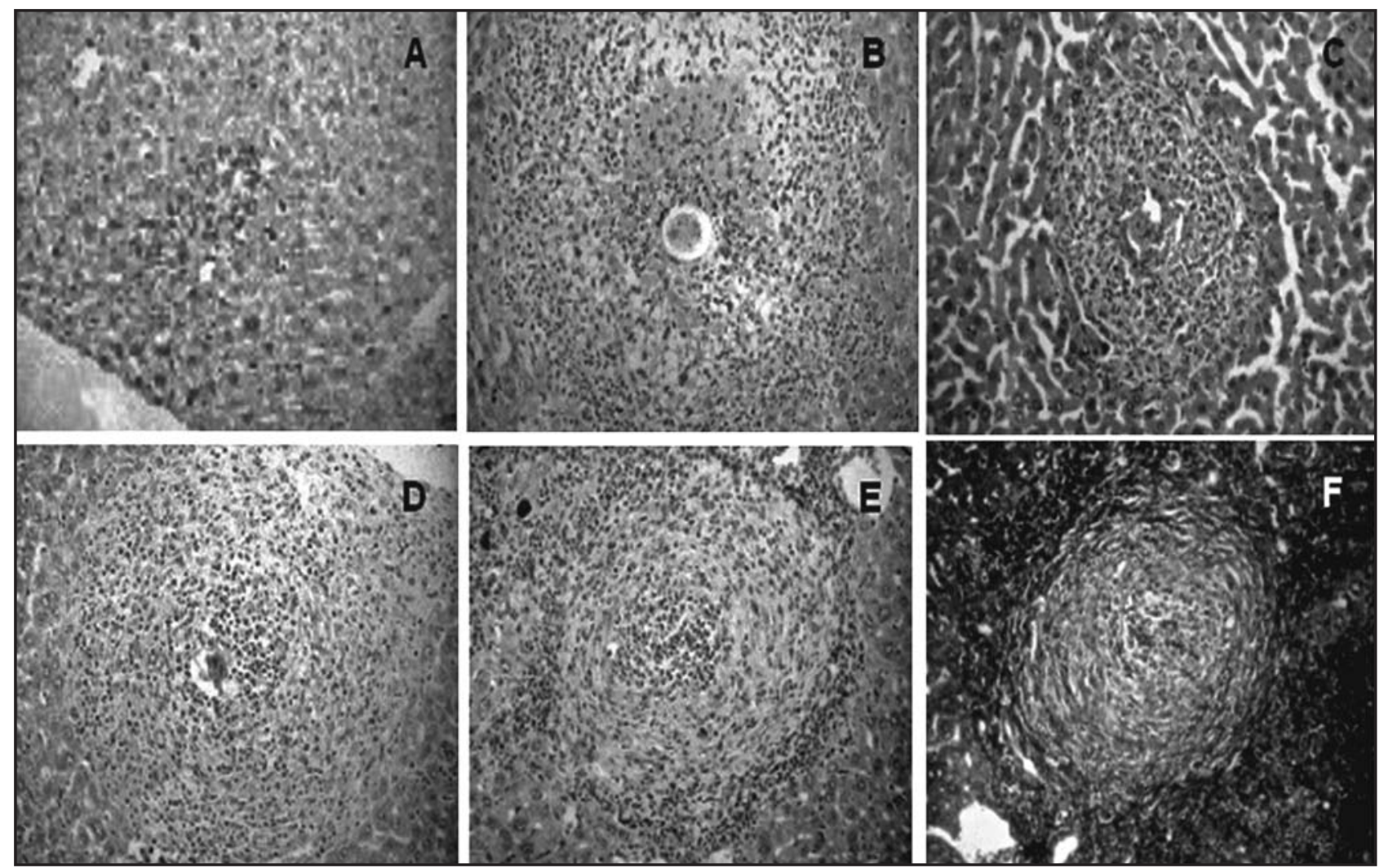

Figura 1 - Evolução do granuloma hepático na esquistossomose mansônica em camundongo. A: Fase pré-granulomatosa de reação inicial (anti-EPO; $40^{\circ}$ dia, após a infecção; 50X). B: Fase pré-granulomatosa exudativa, formando um tecido frouxo de células inflamatórias ao redor do ovo. Notar que alguns sinusóides ainda preservam a sua integridade (HE; $70^{\circ}$ dia após a infecção; 50X). C: Fase necrótico-exudativa, mostrando claramente uma área de necrose entre o ovo e a camada periférica de células inflamatórias (HE; 50 dia após a infeç̧ão; 50X). D: Fase produtiva. Nela há o início da produção de fibras que começam a organizar o granuloma, dando um aspecto circunferencial (HE; $50^{\circ}$ dia após a infecção; $\left.50 X\right)$. E: Fase de cura por fibrose. Uma faixa espessa de fibras é evidente entre o ovo (ou restos dele) e células inflamatórias da periferia. o granuloma pode, então, involuir até desaparecer ou mesmo calcificar (HE; $80^{\circ}$ dia após a infeç̧ão; $50 X$ ). F: Mesmo granuloma de "E", porém corado com tricrômico de M'asson, evidenciando fibras colágenas ( $80^{\circ}$ dia após a infecção; 50x).
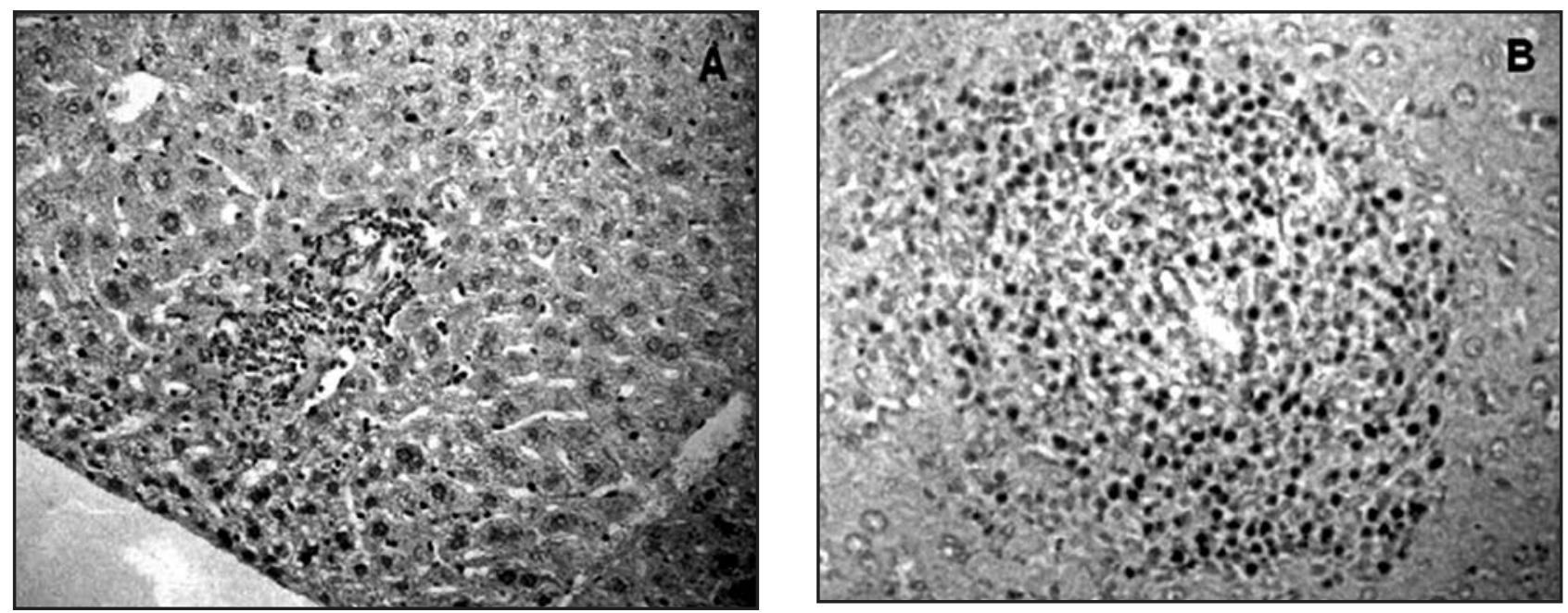

Figura 2 - Padrões de distribuição dos eosinófilos nas fases pré-granulomatosas. A: Fase pré-granulomatosa de reação inicial. Eosinófilos desorganizados (anti-EPO; $40^{\circ}$ dia após a infecção; 50X). B: Fase pré-granulomatosa exudativa. Eosinófilos difusos por toda a área do granuloma (anti-EPO; $45^{\circ}$ dia após a infecção; 100X). 

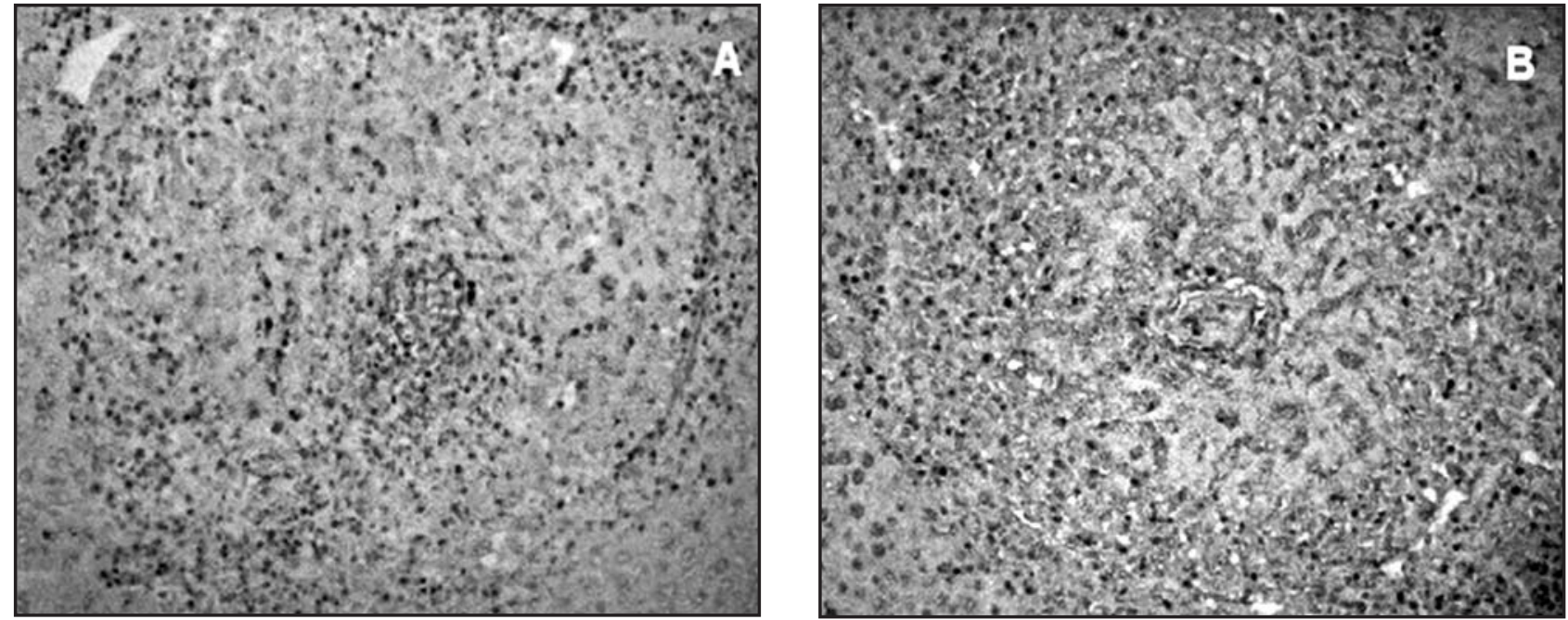

Figura 3 - Padrão de distribuição dos eosinófilos na fase necrótico-exudativa.Os eosinófilos se encontram na periferia e no centro do granuloma em grande densidade. A: Início da fase. Área de necrose maior (anti-EPO; $45^{\circ}$ dia após a infeç̧ão; 50X). B: Final da fase. Células da periferia migrando para ocupar a área de necrose (anti-ECP; 50 dia após a infecção; 50X).
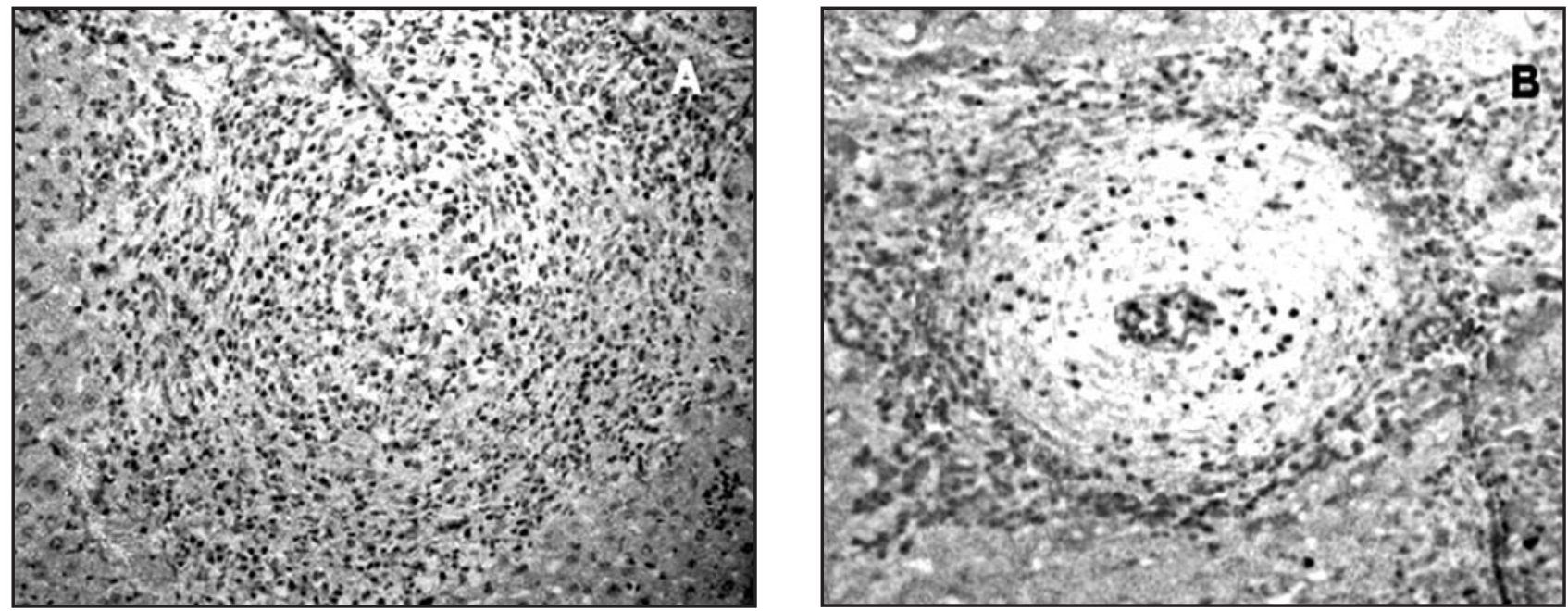

Figura 4 - Padrão de distribuição dos eosinófilos nas fases produtiva e de cura por fibrose. A: Fase produtiva. Eosinófilos difusos por todo o granuloma (anti-EPO; 550 dia após a infecção; 50X). B: Fase de cura por fibrose. Eosinófilos concentrados da periferia, no centro do granuloma e dentro do ovo (anti-EPO; 85으 dia após a infecção; 50X).

\section{DISCUSSÃo}

Em nosso estudo, foi evidenciado que nas fases prégranulomatosas há o recrutamento de células inflamatórias de maneira desorganizada. Porém, aparentemente menos agressivo do que nas fases granulomatosas, os sinusóides ainda são vistos íntegros e as células fagocíticas, mononucleares e eosinófilos estão amplamente distribuídos nos tecidos.

Segundo a literatura, o principal papel da reação granulomatosa na esquistossomose é proteger os tecidos do hospedeiro, isolando as toxinas em potencial secretadas pelo ovo. Após a deposição dos ovos nos tecidos, eles são rapidamente cercados por infiltrados de células inflamatórias, resultando no granuloma. Esse é um processo dinâmico em que o tamanho e a composição celular das lesões variam com o tempo e é coordenado pela influência de uma rede de mediadores inflamatórios ${ }^{323}$.
Eosinofilia, quer localizada ou periférica, junto com altas concentrações de IgE no soro, ocorre com frequiência nas infecções por helmintos ${ }^{19}$. Neste estudo, os eosinófilos formam o maior componente do granuloma hepático do ovo. Algumas das funções designadas para os eosinófilos incluem citotoxidade dependente de anticorpo contra 0 estágio de esquistossômulo ${ }^{21}$ e a destruição de miracídios e ovos ${ }^{3}$.

Antes mesmo do aparecimento de ovos nos vasos hepáticos já existem pequenas reações inflamatórias focais que são inexistentes em cortes do mesmo tecido de camundongos não infectados. Estas reações são geralmente próximas a vasos e coincidem com 0 tempo em que o esquistossômulo se transforma em verme adulto, podendo ser respostas a antígenos solúveis liberados por estes, fato confirmado pelo estudo de Moore ${ }^{15}$. Elas chegam a aumentar cinco vezes o seu tamanho inicial em somente cinco dias de evolução, indicando que há persistência do estímulo. 
0 início da deposição dos ovos pelos vermes adultos de Schistosoma mansoni ocorre por volta do $40^{\circ}$ dia após a infecção e estes focos inflamatórios são vistos no $30^{\circ} \mathrm{e} 35^{\circ}$ dias. Após o $45^{\circ}$ dia da infecção fica difícil distinguir se as reações inflamatórias próximas aos vasos são as mesmas descritas acima ou se são granulomas onde a incidência do corte não foi sobre o ovo.

A partir da avaliação das proteínas eosinofílicas, ficou claro que à medida que o granuloma evolui o nível citoplasmático aumenta significativamente. Segundo Lee \& Lee ${ }^{12}$, os eosinófilos apresentam uma função importante na eliminação de detritos teciduais e as suas proteínas catiônicas ligam-se em praticamente tudo, eles migram para o centro do granuloma quando ocorre a morte espontânea dos miracídios, com liberação de muitos detritos celulares. A própria peroxidase eosinofílica participa na degradação oxidativa de macromoléculas liberadas pela morte celular ${ }^{1420}$.

Também foi constatado que o número das outras células inflamatórias aumenta significativamente entre a fase prégranulomatosa exudativa e a necrótico-exudativa. Esta atinge maiores proporções na etapa aguda da doença ( $45^{\circ}$ dia ao

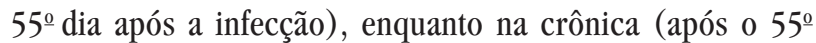
dia da infecção) aparece em menor número. Este fato ocorre, provavelmente, pela rápida oclusão dos vasos, consequiência da microtrombose causada pela exsudação inflamatória.

Os hepatócios adjacentes ao vaso ocluido não têm, portanto, tempo suficiente para adaptar seu metabolismo à baixa oferta de nutrientes e iniciam o processo de necrose. Já na etapa crônica da esquistossomose muitos vasos já foram ocluídos, diminuindo mais lentamente a oferta de nutrientes ao órgão como um todo. As células se tornam, então, mais tolerantes à deficiência nutricional por um granuloma incidente. Motivo pelo qual acreditamos que alguns granulomas que iniciam a sua formação na etapa aguda da doença não atravessam a fase necrótico-exudativa. A fase produtiva viria, neste caso, após a pré-granulomatosa exudativa e teria proporções menores.

A fase produtiva corresponde, como o nome já sugere, ao início da produção de fibras e ocorre após a absorção e fagocitose dos restos celulares decorrentes da necrose dos hepatócitos. As células vão ocupando rapidamente o local da necrose, podendo o tamanho do granuloma diminuir por pressão do tecido vizinho ou manter-se constante ${ }^{12}$.

0 número de células total e aparente ainda é grande e elas começam a se organizar juntamente com os feixes de fibras colágenas num padrão circular em torno do ovo que se completará na fase de cura por fibrose ${ }^{18}$.

A fase de cura por fibrose é caracterizada por uma espessa camada de fibras colágenas circular, isolando completamente o ovo. É comum nesta fase encontrar células inflamatórias, principalmente eosinófilos, dentro da casca do ovo ${ }^{18}$.

A formação da faixa de fibrose envolvendo o ovo na fase de cura por fibrose mantém os eosinófilos dispostos na periferia e no centro do granuloma, de maneira semelhante a da fase necrótico-exudativa.

Nenhuma das classificações publicadas na literatura e revisadas neste estudo se encaixou perfeitamente com os dados obtidos. Portanto, sugerimos uma modificação na classificação para a evolução do granuloma hepático de camundongos infectados por Schistosoma mansoni, montada a partir de fases descritas por outros pesquisadores ${ }^{313}$ : Fase pré-granulomatosa de reação inicial (PRI); fase pré-granulomatosa exudativa (PE); fase necrótico-exudativa $(\mathrm{NE})$; fase produtiva $(\mathrm{P})$; fase de cura por fibrose (CF), acrescidos então, dos dados referentes à dinâmica de distribuição dos eosinófilos.

Em cada fase da evolução do granuloma hepático de camundongos, infectados por Schistosoma mansoni, foi encontrado um padrão diferente de distribuição dos eosinófilos. Na fase pré-granulomatosa de reação inicial os eosinófilos encontram-se desorganizados ao redor do ovo e em pequeno número; a fase pré-granulomatosa exudativa, difusos por todo o granuloma e em maior número. Na fase necrótico-exudativa os eosinófilos encontram-se concentrados na periferia e no centro do granuloma, e na área de necrose eles são escassos. Na fase produtiva, apesar de ocorrer o início da formação de fibras, os eosinófilos estão ainda distribuídos de maneira difusa por todo 0 granuloma; na fase de cura por fibrose concentram-se na periferia e no centro do granuloma, estando em menor número do que na fase necrótico-exudativa e fase produtiva, porém também vistos no interior do ovo.

A partir destes dados, pode-se concluir que a dinâmica dos eosinófilos possui papel importante na formação da reação granulomatosa do hospedeiro e resolução do processo inflamatório causado pelo ovo do parasita e esse conhecimento pode acrescentar novos dados na classificação dos granulomas hepáticos.

\section{REFERÊNCIAS}

1. Ackerman SJ, Gleich GJ, Loegering DA, Richardson BA, Butterworth AE. Comparative toxicity of purified human eosinophil granule cationic proteins for schistosomula of Schistosoma mansoni. The American Journal of the Tropical Medicine and Hygiene 34: 735-745, 1985.

2. Butterworth AE, Wasson DL, Gleich GJ, Loegering DA, David JR. Damage to schistosomula of Schistosoma mansoni induced directly by eosinophil mayor basic protein. Journal of Immunolology 122: 221-229, 1979.

3. Conlon CP. Schistosomiasis. Medicine 31: 64-67, 2005.

4. Farah IO, Nyindo M, King CL, Hau J 2000. Hepatic Granulomatous Response to Schistosoma mansoni eggs in BALB/c Mice and Olive Baboons (Papio cynocephalus anubis). Journal of Comparative Pathology 123: 7-14, 2000.

5. Gleich GJ, Adolphson CR The eosinophilic leukocyte: Structure and function. Advances of Immunology 39: 177-253, 1986.

6. Gryseels B, Polman K, Clerinx J, Kestens L. Human schistosomiasis. Lancet 368: 1106-1118, 2006.

7. James SI, Colley DG. Eosinophilin mediated destruction of Schistosoma mansoni eggs. III. Lymphokine involvement in the induction of eosinophil functional abilities. Cellular Immunology 38: 48-58, 1978.

8. Jong EC, Mahmoud AAF, Klebanoff SJ. Peroxidase-mediated toxicity to schistossomula of Schistosoma mansoni. Journal of Immunology 126: 468-471, 1981.

9. Katz N, Peixoto SV. Critical analysis of the estimated number of schistosomiasis mansoni carriers in Brazil. Revista da Sociedade Brasileira de Medicina Tropical 33: 303-308, 2000.

10. Kephart GM, Andrade ZA, Gleich GJ Localization of eosinophil major basic protein onto eggs of Schistosoma mansoni in human pathologic tissue. American Journal of Pathology 133: 389-396, 1988. 
11. Kierszenbaum F, Ackerman SJ, Gleich GJ. Destruction of bloodstream forms of Trypanosoma cruzi by eosinophil granule mayor basic protein. The American Journal of Tropical Medicine and Hygiene 30: 775-779, 1981.

12. Lee JJ, Lee NA. Eosinophil degranulation: an evolutionary vestige or a universally destructive effector function? Clinical and Experimental Allergy 35: 986-994, 2005.

13. Lenzi HL, Kimmel E, Schechtman H, Machado MP, Romanha WSR, Pacheco RG, Mariano M, Lenzi JA. Histoarchitecture of schistosomal granuloma development and Involution: morphogenetic and biomechanical approaches. Memórias do Instituto Oswaldo Cruz 93: 141-151, 1998.

14. Mitra SN, Slungaard A, Hazen SL. Role of eosinophil peroxidades in the origins of protein oxidation in asthma. Redox Report 5: 215-224, 2000.

15. Moore DL, Groove DI, Warren KS. The Schistosoma mansoni egg granuloma: Quantification of cell population. Journal of Pathology 121: 41-50, 1977.

16. Neves DP. Parasitologia Humana. 10 edição, Editora Atheneu. Rio de Janeiro, RJ, 2000 .

17. Özer E, Sarioglu S, Güre A. Effects of prenatal ethanol exposure on neuronal migration, neurogenesis and brain myelination in the mice brain. Clinical Neuropathology 19: 21-25, 2000.
18. Ribeiro PJ, Aguiar LAK, Toledo CF. Educational program in schistosomiasis: a model for a methodological approach. Revista de Saúde Pública 38: 415-421, 2004.

19. Rothenberg ME, Ownbey R, Mehlop PD, Loiselle PM, van de Rijn M, Bonventre JV, Oettgen HC, Leder P, Luster AD. Eotaxin triggers eosinophil selective chemotaxis and calcium flux via a distinct receptor and induces pulmonary eosinophilia in the presence of IL-5. Molecular Medicine 2: 334-348, 1996.

20. Shen $\mathrm{Z}, \mathrm{Wu}$ W, Hazen SL. Activated leukocytes oxidatively damage DNA, RNA, and nucleotide pool through halide-dependent formation of hydroxyl radical. Biochemistry 39: 5474-5482, 2000

21. Swartz JM, Dyer KD, Cheever AW, Ramalingam T, Pesnicak LD, Joseph B; Lee JJ, Nancy A, Foster PS. Schistosoma mansoni infection in eosinophil lineage-ablated mice. Blood 108: 2420-2427, 2006.

22. Yachnis AT, Trojanowski JQ. Studies of childhood brain tumors using Immunohistochemistry and microwave technology: methodological considerations. Jounal of Neuroscience Methods 55: 191-200, 1994.

23. Wynn TA, Cheever AW. Cytokine regulation of granuloma formation in schistosomiasis. Current Opinion in Immunology 7: 505-511, 1995. 